\title{
COMBATE \\ À PANDEMIA \\ DO CORONAVÍRUS: \\ O DILEMA DA \\ COMUNICAÇÃO VERTICAL \\ EM SOCIEDADES \\ MULTILINGUES - \\ O CASO \\ DE MOÇAMBIQUE
}

\author{
COMBATIR LA PANDEMIA DE CORONAVIRUS: EL DILEMA DE LA COMUNICACIÓN \\ VERTICAL EN SOCIED ADES MULTILINGÜES: EL CASO DE MOZAMBIQUE \\ COMBATING THE CORONAVIRUS PANDEMIC: THE DILEMMA OF VERTICAL \\ COMMUNICATION IN MULTILINGUAL SOCIETIES - THE CASE OF MOZAMBIQUE
}

Manuel Armando Guissemo*

Walter Eusébio Matimbe**

Universidade Eduardo Mondlane | Moçambique

RESUMO: O presente artigo faz uma reflexão sobre o dilema da comunicação vertical em sociedades multilingues. O principal objectivo que se persegue nele é o de fazer uma abordagem da gestão do multilinguismo, tomando o contexto moçambicano como exemplo, caracterizado pela coexistência do Português com as línguas locais africanas, faladas pela maioria da população. O estudo

* Professor Auxiliar da Universidade Eduardo Mondlane, Moçambique, doutorado em Bilinguismo pela Universidade de Estocolmo, Suécia. Docente das disciplinas de Introdução à Antropologia Linguística, Fundamentos de Sociolinguística ( graduação) e Sociologia da Linguagem (pós-graduação).

E-mail: mguissemo@hotmail.com

** Assistente universitário da Universidade Eduardo Mondlane, Moçambique, doutorando em Linguística na mesma instituição. Docente das disciplinas de Introdução à Antropologia Linguística, Fundamentos de Antropologia Linguística, Fundamentos de Sociolinguística e Metodologia de Investigação (graduação). E-mail: maotimbe@yahoo.com.br. 
é feito considerando-se a relação entre a conceitualização da comunicação vertical e as ideologias linguísticas. Metodologicamente, os dados analisados foram recolhidos aleatoriamente na paisagem linguística da cidade de Maputo, inspirando-se no estudo de Landry e Bourhis (1997), e nos mídia locais para captar como o multilinguismo é usado na difusão das informações sobre a prevenção do Coronavírus. Esta informação foi cruzada com abordagens sobre a gestão do multilinguismo.O artigo pretende contribuir nos debates sobre o Multilinguismo, visando apontar para o tipo de ascensão que as línguas locais africanas tendem a ter, do ponto de vista estatutário, num contexto em que elas convivem com o Português, língua com um largo histórico de supremacia. Nele concluímos que as línguas locais africanas permanecem marginalizadas, apesar de parecerem fornecer evidências em contrário devido ao discurso do dia que propala uma convivência cada vez crescente e harmoniosa entre o Português e as línguas locais africanas faladas pelos moçambicanos.

PALAVRAS-CHAVE: Moçambique. Multilinguismo. Pandemia do Coronavírus, Comunicação vertical. Ideologia linguística.

RESUMEN: Este artículo reflexiona sobre el dilema de la comunicación vertical en sociedades multilingües. El principal objetivo que se persigue en él es abordar la gestión del multilingüismo, tomando como ejemplo el contexto mozambiqueño, caracterizado por la convivencia del portugués con las lenguas africanas locales, habladas por la mayoría de la población. El estudio se realiza considerando la relación entre la conceptualización de la comunicación vertical y las ideologías lingüísticas. Metodológicamente, los datos analizados fueron recolectados aleatoriamente del paisaje lingüístico de la ciudad de Maputo, a partir del estudio de Landry y Bourhis (1997), y de los medios locales para capturar cómo se utiliza el multilingüismo en la difusión de información sobre la prevención del coronavirus. Esta información se comparó con enfoques para gestionar el multilingüismo. El artículo pretende contribuir a los debates sobre el multilingüismo, apuntando a señalar el tipo de auge que tienden a tener las lenguas africanas locales, desde el punto de vista estatutario, en un contexto en el que conviven con el portugués, una lengua de larga tradición histórica de supremacía. En él, llegamos a la conclusión de que las lenguas africanas locales siguen marginadas, a pesar de parecer evidencia de lo contrario debido al discurso de la época que promueve una convivencia cada vez mayor y armoniosa entre el portugués y las lenguas africanas locales habladas por los mozambiqueños.

PALABRAS CLAVE: Mozambique. Multilingüismo. Pandemia de Coronavírus. Comunicación vertical. Ideología lingüística.

ABSTRACT: This article reflects on the dilemma of vertical communication in multilingual societies. The main objective pursued in it is to approach the management of multilingualism, taking the Mozambican context as an example, characterized by the coexistence of Portuguese with the local African languages, spoken by the majority of the population. The study is carried out considering the relationship between the conceptualization of vertical communication and linguistic ideologies. Methodologically, the analyzed data were collected randomly from the linguistic landscape of Maputo city, drawing on the study by Landry and Bourhis (1997), and from the local media to capture how multilingualism is used in the dissemination of information about the prevention of Coronavirus. This information was cross-referenced with approaches to managing multilingualism. The article intends to contribute to debates on Multilingualism, aiming to point to the kind of rise that local African languages tend to have, from a statutory point of view, in a context in which they coexist with Portuguese, a language with a long history of supremacy. In it, we conclude that local African languages remain marginalized, despite appearing to provide evidence to the contrary due to the discourse of the day that promotes an ever-growing and harmonious coexistence between Portuguese and the local African languages spoken by Mozambicans.

KEYWORDS: Mozambique. Multilingualism. Coronavirus Pandemic. Vertical communication. Linguistic ideology.

\section{INTRODUÇÃO}

"Ideologias e práticas linguísticas" têm sido um tema de investigação na Sociolinguística africana desde que o continente libertouse do domínio colonial europeu, há mais de 60 anos (KAMWANGAMALU, 2019). Firmino (2002) aborda esse assunto como "A 'Questão Linguística' na África Pós-Colonial”. A essência das investigações nesse âmbito assenta na gestão do multilinguismo no continente africano, tendo em conta que em muitos países deste continente, as línguas locais faladas pela maioria dos africanos não ganharam a esperada valorização a ponto de substituírem as línguas dos ex-colonos da posição de línguas oficiais e línguas mais privilegiadas. Adotar uma política exoglóssica (adoção de uma língua estrangeira como o único idioma oficial nacional) era 
geralmente considerada a escolha mais óbvia em muitos países africanos, após a sua independência (HEINE, 1977; RUIZ, 1995). Devido a essa realidade, atualmente, um dos temas frequentemente tratados na investigação sobre questões linguísticas africanas tem a ver com a necessidade de se "desenvolver", "elaborar" e "promover" a utilização das línguas africanas locais para que possam servir propósitos novos e científicos (MAKONI; MEINHOF, 2003).

No âmbito da temática em torno da coexistência de línguas na África, o presente artigo discute a convivência entre as diversas línguas locais africanas faladas em Moçambique, como línguas maternas de grande parte dos cidadãos, com o Português, língua excolonial e única língua oficial no país. Este artigo pretende contribuir com os debates sobre a gestão do multilinguismo no contexto sociolinguístico moçambicano (STROUD, 2002; LOPES, 2004; FIRMINO, 2002, 2010, 2011; STROUD; GUISSEMO, 2017; GUISSEMO, 2018; REITE et al., 2020; REITE, 2021), em que o principal objetivo é discutir o processo dinâmico associado ao multilinguismo, considerando-se a possibilidade de diferentes línguas serem institucionalizadas na sociedade moçambicana.

O artigo faz uma análise da forma como o multilinguismo é gerido em Moçambique, no contexto da comunicação das principais mensagens de prevenção ao Coronavírus. Nele, concluímos que, nas campanhas de prevenção contra a pandemia do Coronavírus, o uso das línguas locais africanas indicia que essas línguas começam a desempenhar um papel de agências de desenvolvimento no país e que, embora tenham uma crescente visibilidade, o discurso vertical mostra que o português continua sendo a língua, de fato, mais privilegiada nos processos de gestão do país, incluindo o tratamento do multilinguismo.

O primeiro caso de Coronavírus no país foi reportado em Março de 2020, e, a essa altura, criou-se a palavra de ordem "Fique Em Casa” como a principal arma de combate à transmissão do Coronavírus. A par da palavra de ordem "Fique Em Casa”, foram produzidos panfletos explicativos sobre a prevenção do Coronavírus. Diariamente, o Ministério da Saúde também faz um informe sobre o estágio da evolução da pandemia, e o Presidente da República, quando necessário, dirige-se à nação para falar sobre a visão do governo moçambicano relativa à mitigação das consequências nefastas desta pandemia.

Tratando-se de uma crise sanitária global em que a comunicação sobre a sua prevenção deve chegar a todos os cidadãos, interessanos, neste artigo, refletir sobre a forma de gestão que o governo de Moçambique tem usado para gerir o multilinguismo, de modo a garantir que a informação oficial relacionada ao combate à pandemia do Coronavírus alcance a todos os cidadãos. Nesse sentido, a reflexão foi feita através de dados recolhidos aleatoriamente na paisagem linguística da cidade de Maputo, inspirando-se no estudo de Landry e Bourhis (1997), e nas mídias locais, nomeadamente, televisões locais, jornais em circulação na cidade e Rádio Moçambique, para captar como o multilinguismo é usado na difusão das informações sobre a prevenção do Coronavírus. Essa informação foi cruzada com abordagens sobre a gestão do multilinguismo.

O presente artigo começa com uma introdução na qual se apresenta o âmbito do estudo no contexto do multilinguismo. Depois da introdução, apresenta-se a descrição sociolinguística do sul de Moçambique, que é a zona que foi alvo de estudo. Posteriormente, trata-se da conceitualização da comunicação vertical, considerando-se inicialmente o contexto africano e depois o caso de Moçambique. Na quarta parte do artigo aborda-se a questão do multilinguismo em contextos pós-coloniais, tendo em conta o tipo de ideologia que pode estar associada à gestão da coexistência das línguas locais africanas com a língua do ex-colono. A essa parte segue a apresentação de alguns estudos sobre as ideologias linguísticas na África, com especial destaque para Moçambique. A penúltima parte do artigo é direcionada para a análise do dilema da comunicação vertical no contexto moçambicano, em tempos da pandemia do Coronavírus. Por fim, segue a conclusão com a apresentação das observações finais.

\section{DESCRIÇÃO SOCIOLINGUÍSTICA (DO SUL) DE MOÇAMBIQUE}

Moçambique é um país multilingue localizado no Sul Global e faz fronteira com seis países que foram colônias britânicas, nomeadamente República Unida da Tanzânia, Malawi, Zâmbia, Zimbabwe, África do Sul e Reino de Eswatini. Em Moçambique, o Português, língua do ex-colono, é a língua oficial e coexiste com mais de uma dezena de línguas locais africanas, também conhecidas como línguas bantu. Essas línguas locais africanas constituem o maior substrato linguístico do país e são faladas como línguas maternas por mais de 85\% da população total (CHIMBUTANE, 2012, p. 5). O mosaico linguístico em Moçambique é enriquecido 
com a presença de algumas línguas de origem asiática, como o Gujarati, o Memane, o Hindi e o Urdu (LOPES, 2004, p. 18), bem como com a presença de algumas línguas africanas trazidas por imigrantes de países como Nigéria, Sudão, Somália, República Democrática do Congo e Ruanda (CHIMBUTANE, 2015), existindo, também, falantes de algumas línguas europeias, como o francês e o inglês. O número de moçambicanos que fala inglês tem vindo a crescer devido às vantagens profissionais e educacionais relacionadas com essa língua (ROSÁRIO, 2015; FIRMINO, 2010; STROUD, 2002). O multilinguismo em Moçambique é, também, caracterizado pela presença do português brasileiro e do chinês (para mais detalhes, veja GUISSEMO [2018]).

Durante o período colonial, "as línguas africanas e o Português foram enquadrados de formas diferenciadas (...) e organizados em diferentes ordens de visibilidade" (STROUD; GUISSEMO, 2015, p. 9). O Português estava ligado a domínios e funções públicas e oficiais e à ideia de modernidade e metrópole, enquanto as línguas africanas eram restritas a domínios informais, domésticos, e ligadas à ideia de tradicional e local (STROUD, 2007, p. 30; FIRMINO, 2002).

Quando da independência de Moçambique, proclamada em 25 de junho de 1975, "[...] a língua portuguesa era parte do repertório linguístico de um grupo minoritário de moçambicanos, residentes principalmente nos centros urbanos" (GONÇALVES, 2010, p. 31). Apesar desse cenário, o governo moçambicano liderado pela Frelimo adotou uma política linguística exoglóssica, através da qual o Português foi declarado a língua oficial e língua-de unidade nacional. Para Gonçalves (2010),

A atribuição deste estatuto oficial à língua portuguesa prende-se, em primeiro lugar, com as suas potencialidades como língua "operacional" (GANHÃO, 1979), que garante a unidade nacional e permite, de forma mais eficaz do que as línguas bantu locais, a comunicação internacional e a transmissão de conhecimento científico. (GONÇALVES, 2010, p. 31)

Uma análise baseada nos dados do censo feito pelo Instituto Nacional de Estatística Moçambicano, referente aos períodos de 19802017, mostra que as línguas locais africanas continuam a ser largamente usadas em Moçambique. A nível nacional, o emakhwua é a maior língua materna, seguida do português e do xichangana (REITE, 2021; INE, 2019, CHIMBUTANE, 2012; FIRMINO, 2002). Apesar do crescente uso das línguas locais africanas, essas línguas ainda não possuem a visibilidade e o estatuto que o Português possui no país (GUISSEMO, 2018, p. 12), sendo as línguas locais africanas usadas, principalmente, na comunicação intra-étnica.

Na região sul de Moçambique, a capital do país, Maputo, objeto do presente estudo, as práticas linguísticas são caracterizadas, principalmente, pelo uso de três línguas dominantes nessa região, o português, o xichangana e o xirhonga. O português é substancialmente mais usado nas áreas urbanas, e o xichangana e o xirhonga são mais usados nas áreas suburbanas e rurais. Na cidade de Maputo, o xirhonga e o xichangana são as línguas nativas e as primeiras línguas de comunicação para a maioria dos residentes, e essas línguas são usadas preferencialmente nos domínios privados (FIRMINO, 2002). Em estudo mais recente, Reite (et al., 2020) constataram que na capital do país mais da metade dos jovens com menos de 20 anos declara usar o português como a principal língua de comunicação, em um contexto linguístico em que também se usa o xichangana, o xirhonga e, em alguns casos, o inglês.

O uso constante do xichangana e xirhonga pela maioria dos residentes na capital do país permite que essas duas línguas sejam consideradas como línguas francas na cidade de Maputo (FIRMINO, 2002). Para terminar a caracterização do contexto sociolinguístico dessa cidade, importa referir que a cidade de Maputo, sendo a capital do país, devido aos movimentos migratórios internos de outras províncias para essa cidade, incluindo a presença de pessoas de outros países, registra a circulação, com grande ou pequena incidência, de quase todas as línguas anteriormente descritas como integrantes do cenário sociolinguístico moçambicano. 


\section{SOBRE O CONCEITO DE COMUNICACÃO VERTICAL}

O processo de comunicação entre o poder político e as massas pode ser executado por via de mecanismos que se designam por comunicação vertical e comunicação horizontal. Tomando como base o estudo de Heine (1977), intitulado comunicação vertical e horizontal na África, explicaremos o alcance desses dois conceitos.

Heine (1977) explica que a comunicação vertical pode ser empregada como um símbolo de autoridade, sinalizando superioridade sobre os outros enquanto o uso da comunicação horizontal, por outro lado, cria o efeito oposto, isto é, pode ser empregada para minimizar as aspirações pessoais e enfatizar atitudes igualitárias.

Em termos de função social, Heine (1977) afirma que a comunicação vertical é usada, inter alia, a fim de estabelecer a distância social entre o orador e o ouvinte e para criar um ambiente de relacionamento formal, enquanto a comunicação horizontal é usada para servir a funções opostas às acima descritas. A comunicação horizontal serve para suprir as lacunas que podem separar os participantes no processo comunicativo e/ou introduzir uma atmosfera de informalidade na conversa (HEINE, 1977, p. 234). A título exemplificativo, Heine (1977) explora o estudo de David Parkin (1974), que fala sobre a situação linguística em Nairobi, onde se observa que o inglês funciona como uma língua vertical, e o swahili funciona como uma língua horizontal. Segundo as palavras de David Parkin, citado por Heine (1977, p. 234, tradução nossa): “[...] se eu for um funcionário do governo, o uso do Inglês pode afirmar a minha autoridade e estabelecer um tom de formalidade... Se a pessoa não souber o Inglês, ela provavelmente dará as boas vindas (usando o Swahili), o que é menos humilhante para ele do que o recuo no estatuto implícito pela mudança do Inglês para o Swahili" ${ }^{1}$.

É nosso entendimento que a comunicação horizontal é feita, muitas vezes, com recursos às línguas consideradas marginais. De acordo com Guissemo (2018), as línguas locais africanas, faladas pela maioria da população, foram ideologicamente enquadradas como marginais, periféricas, irrelevantes e, por vezes, totalmente contrárias ao desenvolvimento do país durante os períodos colonial e pós-colonial. Guissemo (2018) argumenta que em diferentes momentos históricos, as línguas locais africanas foram proibidas (especialmente em alguns espaços urbanos), censuradas, tornadas invisíveis e monitoradas, e os seus falantes vigiados. Recentemente, no início da década de 90, as línguas locais africanas atingiram um ponto "na ordem de visibilidade" 2 que se pode considerar como de "reconhecimento ou afirmação" (KERFOOT; HYLTENSTAM, 2017). Mas, mesmo assim, esse reconhecimento vem embalado por várias formas de marginalidade (GUISSEMO, 2018). Em Moçambique, ainda é notório que as línguas locais africanas não adquiriram a merecida cidadania, elas sempre aparecem à sombra da língua portuguesa, língua eleita como oficial e de unidade nacional. Evidencia essa realidade, por exemplo, o fraco uso que essas línguas têm tido a nível das televisões nacionais e da imprensa escrita.

\section{MULTILINGUISMO EM CONTEXTOS PÓS-COLONIAIS}

O período colonial foi em grande medida dominado pelas "[...] ideologias de homogeneidade e uniformidade que se sobrepunham à diversidade social que caracterizava todo ambiente social" (DONG; BLOMMAERT, 2009, p. 47). No período pós-colonial, verifica-se o abandono da estabilidade e homogeneidade linguísticas como normas para dar espaço à diversidade linguística (HELLER, 2011).

O multilinguismo em contextos pós-coloniais tem despertado cada vez mais interesse à Sociolinguística devido às suas diferentes gêneses e dinâmicas. De acordo com Blommaert (2010), muitos dos estudos realizados sobre o multilinguismo em contextos póscoloniais são categorizados por aquilo que se designa por "Sociolinguística da Globalização". Blommaert (2010) sugere que a Sociolinguística da Globalização deve ser uma Sociolinguística de recursos comunicativos móveis e não de línguas imóveis, porque

\footnotetext{
1 "If I am a government officer, use of English may affirm my authority and set a tone of formality... If the man does not know English then he is likely to welcome (using Swahili), which is less humiliating to him than the stepdown in status implied by the switch from English to Swahili." (PARKIN, 1974, p. 208).

${ }^{2}$ In the order of visibility.
} 
a mobilidade afeta a linguagem. Assim, estudos sobre esse fenômeno têm de ter em conta que as línguas podem entrar em novos espaços, bem como podem ser associadas a novos valores.

As dinâmicas do multilinguismo nos países do sul global têm sido objeto de estudo e com base na sua análise, pode-se notar que a escolha, o uso e as atitudes no âmbito linguístico estão intrinsecamente ligadas às ideologias linguísticas, às relações de poder, aos arranjos políticos e às identidades dos falantes (BLACKLEDGE, 2009, p. 35).

Ideologias linguísticas podem ser definidas como "[...] o sistema cultural de ideias sobre relações sociais e linguísticas, juntamente com sua carga de interesses morais e políticos" (IRVINE, 1989, p. 255). Assim, as ideologias linguísticas nunca são apenas sobre a linguagem, mas, também, dizem respeito a noções sociais fundamentais, como comunidade, nação e a própria humanidade (WOOLARD, 2004, p. 58). Blommaert (1999), na sua obra Language Ideological Debate, afirma que as ideologias linguísticas estão, também, relacionadas com o estabelecimento de relações políticas de poder, dominação e exploração por meio de uso de certas línguas que dão vantagens a certos grupos dentro de uma sociedade específica. Ainda nessa obra, Blommaert afirma que para o caso específico de África, os debates em torno das ideologias linguísticas são fundamentais para entender como "o multilinguismo é encarado como um obstáculo e como algo que deve ser enfrentado por meio de planeamento, políticas e intervenções especializadas" (BLOMMAERT, 1999, p. 25).

No presente artigo, a análise da questão da comunicação vertical será alicerçada na abordagem centrada na ideologia linguística. Blommaert (1999) sugere que a ideologia linguística é um tópico importante de debate no estudo da relação entre a linguagem e a sociedade, especialmente quando se trata da abordagem de tópicos relacionados com a relação entre a linguagem e as estruturas sociais e poder, e dos motivos e causas de certos tipos de mudanças linguísticas. Considerando este posicionamento, acreditamos que as opções linguísticas num contexto multilingue como o moçambicano também podem estar relacionadas com as ideologias linguísticas.

\section{ALGUNS ESTUDOS SOBRE AS IDEOLOGIAS LINGUÍSTICAS NA ÁFRICA}

Madumulla (et al., 1999), num estudo sobre ideologias linguísticas na Tanzânia, constataram que a transição política para o socialismo intensificou o processo de construção da nação tanzaniana, tendo o recurso à promoção do swahili para o estatuto de língua nacional contribuído para esse feito. Essa mudança na política linguística foi entendida como um processo de "africanização" da nação pós-colonial (BLOMMAERT, 1999, p. 26). Guissemo (2018) entende que a revolução socialista na Tanzânia deu visibilidade e cidadania aos falantes de swahili, e como resultado disso essa língua começou a ser usada por intelectuais na poesia.

No contexto moçambicano, retratado por Stroud (1999), observa-se uma realidade que se distancia muito da ideologia linguística adotada na Tanzânia. De acordo com Stroud (1999), a transição política para o socialismo em Moçambique, logo após a independência, em 1975, ditou a promoção do uso da língua do ex-colonizador, o português, como língua oficial e língua de unidade nacional. De acordo, ainda, com Stroud (1999), essa promoção do português em Moçambique foi acompanhada por um conjunto de processos semióticos que enraizaram a língua no imaginário do Estado-Nação. Essa língua tornou-se o meio através do qual o governo socialista exercia o poder e o controle na construção da nação moçambicana.

Stroud e Guissemo (2017) analisaram o multilinguismo em Moçambique dentro da perspectiva dos debates da ideologia linguística (Language Ideological Debate), apontando o seu estudo para as diferentes formas de inserção que as línguas locais africanas e o português foram tendo ao longo do tempo, inseridos em discursos de temporalidade muito diferentes. A conclusão a que se chegou foi a de que as línguas locais africanas são vistas como línguas do passado ou do futuro, em oposição ao português, que é representado discursivamente como uma língua do presente.

Com base na breve abordagem sobre o multilinguismo em contextos pós-coloniais aqui realizada, entendemos que o quadro conceitual da Sociolinguística alicerçada nos padrões contemporâneos de globalização é, também, relevante na investigação e compreensão do multilinguismo no Moçambique colonial e pós-colonial, na medida em que a reconstrução do Moçambique pós- 
colonial foi feita em torno da portuguesificação $0^{3}$ dos espaços urbanos, embora esses espaços já fossem habitados por moçambicanos que, na sua maioria, não falavam português como língua materna (GUISSEMO, 2018). No Moçambique atual, mais constitucional e mais plural, as línguas locais africanas têm uma visibilidade emblemática (uma visibilidade de exibição/promulgação) como itens de patrimônio cultural (STROUD; GUISSEMO, 2015, p. 15), e essas línguas também começam a ser usadas em alguns setores que garantem o desenvolvimento do país. Chimbutane (2017), falando dos múltiplos contextos de uso das línguas locais africanas em Moçambique, afirma que:

Além de suas funções educacionais, as línguas africanas são usadas em campanhas políticas e cívicas, como a prevenção do HIV/SIDA, o que abriu novos e promissores mercados para usuários competentes dessas línguas, incluindo serviços editoriais, de tradução e interpretação. A indústria da informação e comunicação é outro sector que tem exigido pessoal qualificado nas línguas africanas. (CHIMBUTANE, 2017, p. 7)

Tendo caracterizado o tipo de coexistência linguística que se tem observado em Moçambique na edificação e consolidação do Estado-Nação, passamos à análise dos contornos que tem tomado a gestão do multilinguismo em tempos da pandemia do Coronavírus no país.

\section{PANDEMIA DO CORONAVÍRUS E O DILEMA DA COMUNICAÇÃO VERTICAL EM MOÇAMBIQUE}

As informações oficiais relacionadas com a evolução da pandemia do coronavírus no país são veiculadas diariamente pelo Ministério de Saúde (MISAU). O informe do MISAU é realizado em conferência de imprensa dirigida aos jornalistas dos diferentes órgãos de informação. Em tempo útil, alguns órgãos de informação como a TVM, STV ${ }^{4}$ e Rádio Moçambique efetuam a transmissão ao vivo. Em termos linguísticos, o informe do MISAU e a interação realizada com os jornalistas é efetuada exclusivamente em língua portuguesa, havendo a tradução para a língua de sinais na TVM.

A informação sobre a pandemia do Coronavírus no país também é veiculada por meio de panfletos afixados em espaços públicos e com recurso à imprensa escrita. Esses dois mecanismos recorrem exclusivamente à língua portuguesa para a transmissão das mensagens sobre o Coronavírus. Depois de terem sido feitas várias rondas exploratórias na paisagem linguística da cidade de Maputo e sobre os jornais impressos em circulação nessa cidade, não se encontrou um único anúncio/panfleto ou placa publicitária escrito nas línguas locais africanas, embora uma parte considerável dos habitantes desta cidade tenham como língua materna uma língua local africana. A área da Paisagem Linguística (Linguistic Landscape) dedica-se ao estudo da linguagem presente nos espaços públicos. Por consenso, Landry e Bourhis (1997) são atribuídos a autoria do estudo mais marcante nessa área. Os autores afirmam que: "A linguagem dos sinais de trânsito público, outdoors publicitários, nomes de ruas, nomes de lugares, sinais de lojas comerciais e sinais públicos em edifícios governamentais combinam-se para formar a paisagem linguística de um determinado território, região ou aglomeração urbana" (LANDRY; BOURHIS, 1997, p. 25).

A ausência das línguas locais africanas nos anúncios sobre a prevenção do Coronavírus nos jornais e na paisagem linguística mostra que o português é a língua eleita e privilegiada tanto na paisagem linguística como na imprensa escrita moçambicana na campanha sobre a prevenção do coronavírus. Veja-se a imagem 1.

\footnotetext{
${ }^{3}$ Por portuguesificação referimo-nos à promoção exclusiva da língua portuguesa nos espaços públicos. Por exemplo, havia casos em que avisos eram afixados em repartições públicas lembrando às pessoas que era obrigatório o uso do português, a língua oficial (FIRMINO, 2002, p. 235).

${ }^{4}$ TVM - sigla referente à “Televisão de Moçambique”, órgão de comunicação público. STV - sigla referente à “Sua Televisão”, órgão de comunicação privado.
} 


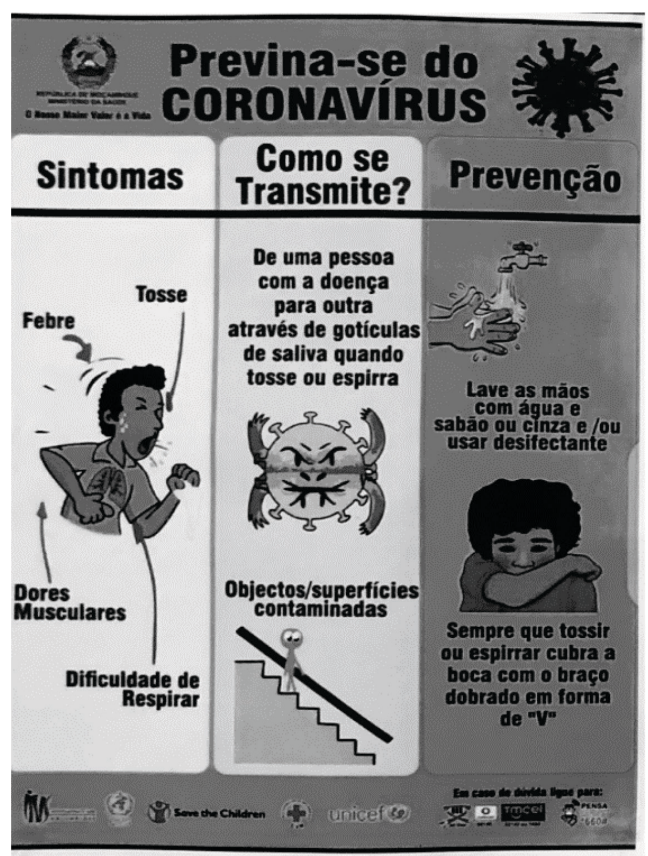

Imagem 1: Panfleto mais publicado no país sobre as medidas de prevenção do Coronavírus

Fonte: MISAU (2020)

Na imagem 1, apresenta-se o panfleto que é amplamente usado na cidade de Maputo, e em todas as províncias do país, na difusão dos sintomas associados ao Coronavírus, bem como na disseminação das medidas de prevenção contra esse vírus. Essa imagem atesta a ausência das línguas locais africanas na comunicação vertical em prol do combate à pandemia, ou seja, na comunicação entre as entidades com poder institucional e a população.

$\mathrm{Na}$ imagem 2, é apresentado panfleto, provavelmente produzido para as zonas rurais, onde se usa, largamente, as línguas locais africanas, tendo em conta o tipo de casa retratada, construída de material local - caniço e com a ausência de água canalizada.

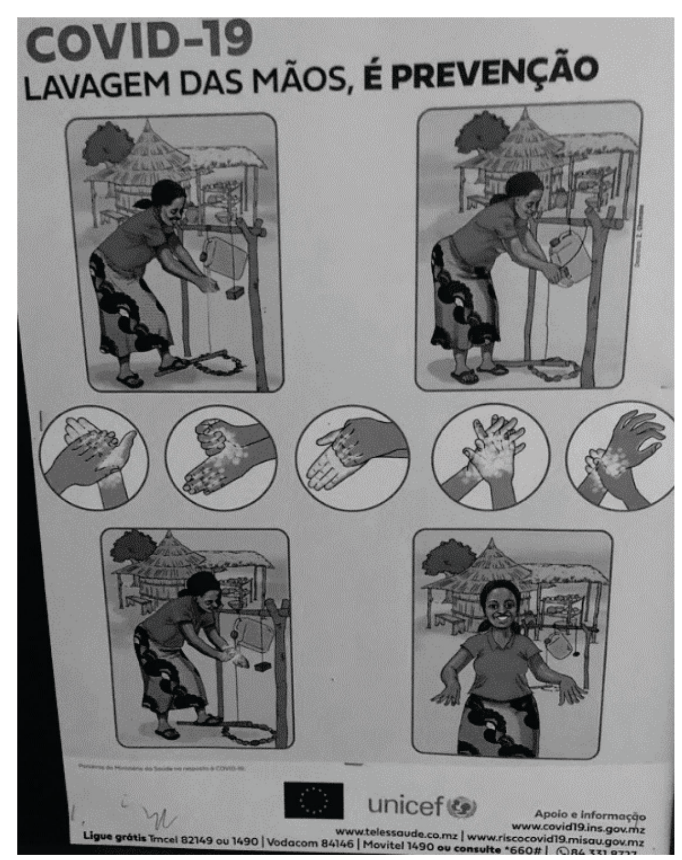

Imagem 2: Panfleto ilustrativo da lavagem das mãos

Fonte: MISAU (2020) 
Na imagem 2, nota-se a ausência de elementos linguísticos na explicação do modo de lavagem das mãos, no entanto, há que se destacar o uso exclusivo da língua portuguesa no cabeçalho do panfleto. A ausência das notas explicativas nessa imagem pode estar relacionada com o não uso das línguas locais africanas na comunicação vertical nos panfletos publicitários sobre a prevenção do Coronavírus.

No âmbito do combate à pandemia do Coronavírus, quando necessário, também o Presidente da República, Filipe Nyusi, dirige-se à nação, tendo, no dia 30 de abril de 2020, feito o anúncio da prorrogação do Estado de Emergência, inicialmente declarado em Março de 2020, por mais 30 dias a contar de $1^{\circ}$ de Maio. No informe, totalmente dirigido em língua portuguesa, o Presidente terminou dizendo "Vamos ficar em Casa". Essa expressão foi, em seguida, repetida em três línguas locais africanas, emakhuwa, cisena e xichangana ${ }^{5}$ :

Emakhuwa-Nrowe ootheene ahu nikhale owaani;

Cisena - Ngatikale pamuzi;

Xichangana - Ahithsameni kaya.

Coincidência ou não, essas três línguas estão geograficamente bem distribuídas em Moçambique. Emakhuwa é a língua com maior número de falantes no país e é muito falada na zona norte. Cisena é uma das línguas faladas na zona centro do país. Xichangana éa língua mais falada na zona sul do país, incluindo a capital.

No seu informe do dia 30 de abril de 2020, o Presidente Nyusi deixou a indicação da necessidade de se usarem as línguas locais no processo de disseminação das informações sobre a prevenção do Coronavírus, como atesta a imagem 3.

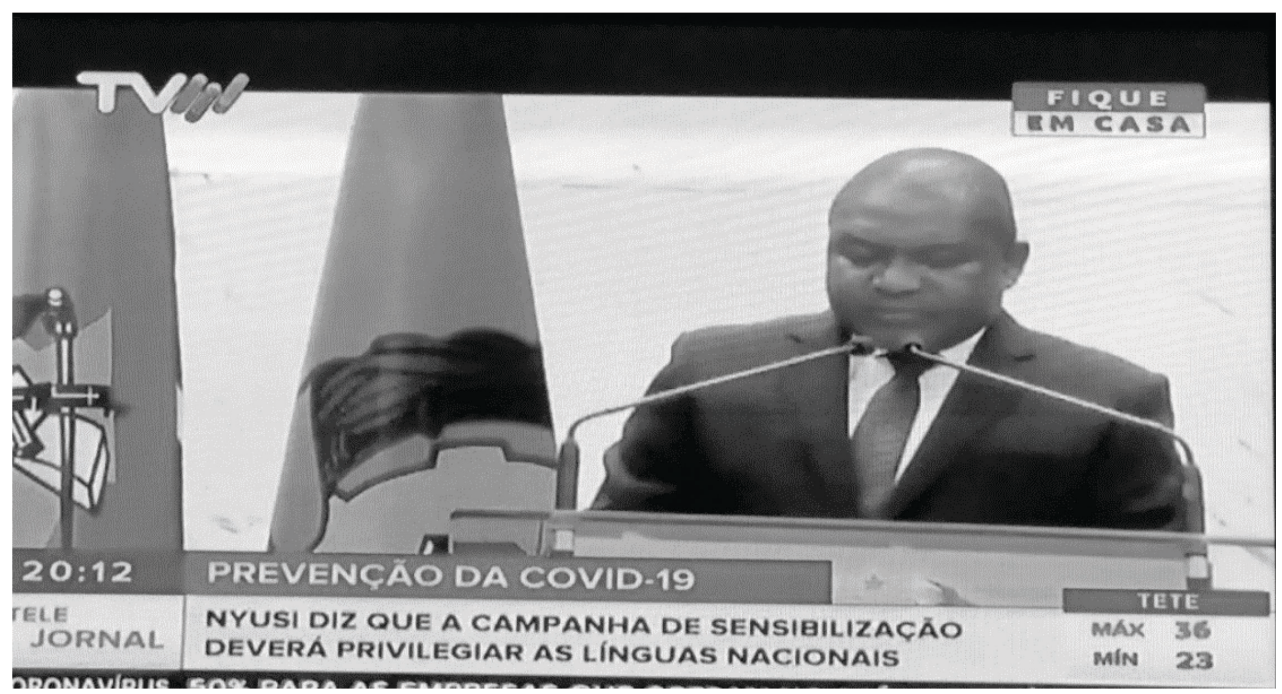

Imagem 3: Presidente da República no informe à nação, dia 30 de abril de 2020

Fonte: TVM (2020)

O uso das línguas locais africanas emakhuwa, cisena e xichangana no discurso à nação foi algo surpreendente e emotivo por não ser habitual o recurso a essas línguas durante os informes oficiais do Presidente da República, uma vez que "[a]s línguas [locais] africanas raramente são percebidas como meios significativos de modernização e progresso" (CHIMBUTANE, 2017, p. 1), devido à herança dos discursos coloniais que viam essas línguas como historicistas, tradicionais, obsoletas (STROUD; GUISSEMO, 2017).

Os discursos locais, em quase todo o país, sobre a prevenção da pandemia do Coronavírus são realizados com recurso às línguas locais africanas, sempre que isso se mostra pertinente para o alcance cada vez maior das massas. No Jornal Notícias, do dia 16 de abril de 2020, numa matéria relativa a "Mensagens sobre prevenção também nas zonas rurais", Anselmo Colher, residente na Vila Municipal de Úlonguè, distrito de Angónia, Tete, disse o seguinte:

${ }^{5}$ Agradecemos ao Dr. Maurício Bernardo pela transcrição dos excertos do discurso do Presidente da República. 
Por aquilo que me tem chegado aos ouvidos, as mensagens disseminadas sobre as medidas de prevenção contra o novo coronavírus são bem claras uma vez que são transmitidas em línguas locais. Por isso não vejo a razão de alguém dizer que não tem conhecimento da existência da doença e muito menos das medidas para a sua prevenção. (JORNAL NOTÍCIAS, 16 de abril de 2020, p. 24)

Entendemos do depoimento que, pelo fato de usarem as línguas locais nas campanhas de sensibilização sobre a prevenção do coronavírus, estão criadas as condições para que todos tenham acesso à informação e estejam em condições de se prevenirem. Essa realidade não seria possível com o uso exclusivo da língua portuguesa, uma vez que o português ainda é uma língua exclusivista, por não ser do domínio de muitos moçambicanos. O apoio ao uso das línguas locais africanas nas zonas rurais no âmbito das mídias moçambicanas pode ser considerado "[u]ma celebração verbal do multiculturalismo do gueto" (PENNYCOOK; MITCHELL, 2009, p. 36), dado que nas "[...] mídias globais: apenas certos tipos de discurso público se tornam hegemónicos e, portanto, a capacidade dos sujeitos marginais de contestar às formas pelas quais são representados, é limitado"(HAUPT, 2013, p. 479).

O uso das línguas locais africanas em domínios oficiais/formais de campanhas de sensibilização traz as populações não falantes do português, que constituem a maioria da população moçambicana, para a construção da nação. Esse é um exemplo daquilo que Stroud (2001) chama de Linguistic Citizenship (cidadania linguística ${ }^{6}$ ). De acordo com Stroud (2001, p. 347, tradução nossa):

O conceito de cidadania linguística é uma forma de reconhecer o enorme potencial político que reside na formulação de representações alternativas e complexas de identidade e linguagem que esperam ser aproveitadas. Ele oferece uma crítica dos discursos dominantes que atribuem uma identidade a uma língua - muitas vezes uma identidade caracterizada em relação às preocupações do Estado majoritário.7

Com base na cidadania linguística, as línguas locais africanas começam a ganhar cada vez mais destaque em lugares multilingues africanos. Esse impulso que se tem dado ao uso das línguas locais africanas no país corresponde à comunicação horizontal, dado que consideramos ser a materialização das orientações com vista a possibilitar maior aproximação entre o Estado e a população no combate à pandemia do Coronavírus. Essas medidas foram resultantes da comunicação vertical em língua portuguesa emanada pelo MISAU e pelo Presidente da República, ou seja, das diretrizes sobre o combate à pandemia do Coronavírus com cunho/poder institucional produzidas em português, visando melhorar a comunicação por meio da inclusão das línguas locais africanas.

A análise feita neste artigo mostra que a aceitação pública das línguas locais africanas em Moçambique é agora um procedimento normal. Estamos em uma nova era em que o valor das línguas locais africanas na paisagem sociocultural moçambicana recebeu alguma forma de reconhecimento "alargado". Esse reconhecimento "alargado" fortalece a ideologia da inclusão social por possibilitar maior participação dos moçambicanos nos processos oficiais, apesar de essas línguas serem usadas para veicular o que foi discutido e deliberado em espaços onde a língua portuguesa é predominante. Nesse sentido, o português ainda está associado a uma retórica de modernidade, antitradicionalismo, urbanização e cooptação de elites, articulando claramente uma continuidade histórica com o português colonial (STROUD; GUISSEMO, 2017).

\section{OBSERVAÇÕES FINAIS}

No sul global, o monolinguismo começa a dar espaço ao multilinguismo, em que as línguas locais africanas estão ganhando cada vez mais visibilidade em ambientes antes reservados ideologicamente às línguas europeias. O presente artigo mostra, conforme foi apontado por Firmino (2011), que o português em Moçambique está imerso em um Estado-Nação multilingue e multicultural, em que as línguas locais africanas cumprem funções instrumentais e sentimentais significativas. A análise da configuração do contexto

\footnotetext{
${ }^{6}$ Tradução nossa.

7 "The concept of linguistic citizenship is one way of recognising the enormous political potential residing in the formulation of alternative and complex representations of identity and language that is waiting to be harnessed. It offers a critique of those dominant discourses that would ascribe one identity in one language - often an identity characterised in relation to the concerns of the majority State”. (STROUD, 2001, p. 347).
} 
sociolinguístico moçambicano aponta para o fato de as línguas locais africanas e do português serem produzidos discursivamente em quadros temporais distintos. É esse fator diferenciador que continua a reproduzir a marginalidade das línguas locais africanas, uma vez que se continua a observar uma supremacia do português, que foi promovido a estatutos altos no período colonial e no início da construção do Estado-Nação.

Este artigo, no âmbito da pesquisa sobre o multilinguismo em Moçambique, argumenta que as línguas locais africanas permanecem marginalizadas, apesar de parecerem fornecer evidências em contrário devido ao discurso do dia que propala uma convivência cada vez mais crescente e harmoniosa entre o português e as línguas locais africanas faladas pelos moçambicanos. Por exemplo, em alguns eventos públicos, como campanhas eleitorais, o uso das línguas locais africanas pelos políticos constitui uma das grandes estratégias de mobilização das massas, não se verificando a mesma preocupação com uso dessas línguas após o término dos períodos de campanha eleitoral.

No que diz respeito às campanhas de prevenção contra a pandemia do Coronavírus, o uso das línguas locais africanas indicia que essas línguas começam a desempenhar um papel de agências de desenvolvimento em Moçambique. Apesar da crescente visibilidade das línguas locais africanas no país, o discurso vertical mostra que o português continua sendo a língua mais privilegiada nos processos de gestão do país, incluindo o tratamento do multilinguismo que esses processos comportam. Essa realidade perpetua, como mostrou Heine (1977), a ideologia europeia que, na África, ditou a adoção do uso das línguas europeias como símbolos unificadores nas unidades geopolíticas caracterizadas pela heterogeneidade étnica e linguística.

\section{REFERÊNCIAS}

BLACKLEDGE, A. Discourse and Power in a Multilingual World. Amsterdam: John Benjamins Publishing Company, 2009.

BLOMMAERT, J. The Sociolinguistics of Globalization. Cambridge: CUP, 2010.

BLOMMAERT, J. The Debate is Open. In: BLOMMAERT, J. (ed.). Language Ideological Debates. Berlin: Mouton de Gruyter, 1999. p. 1-38

CHImbutane, F. Language Policies and the Role of Development Agencies in Postcolonial Mozambique. Current Issues in Language Planning, v.18, n, 4, p. 1-15, 2017.

CHIMBUTANE, F. Línguas e educação em Moçambique: uma perspectiva sócio-histórica. In: GONÇALVES, P.; CHIMBUTANE, F. (org.). Multilinguismo e Multiculturalismo em Moçambique: em direcção a uma coerência entre discurso e prática. Maputo: Alcance Editores, 2015. p. 35-75.

CHImbutane, F. Panorama Linguístico de Moçambique - Análise dos Dados Do III Recenseamento Geral da População e Habitação de 2007. Maputo: INE, 2012.

DONG, J.; BLOMMAERT, J. Space, Scale and Accents: Constructing Migrant Identity in Beijing. In: COLLINS, J.; SLEMBROUCK, S.; BAYNHAM, M. (ed.). Globalization and Language in Contact. Scale, Migration and Communicative Practices. Great Britain: Continuum, 2009. p. 42-61.

FIRMINO, G. Nation-statehood and linguistic diversity in the postcolony: The case of Portuguese and indigenous languages in Mozambique. In: ANCHIMBE, E; MFORTEN, S. (ed.). Postcolonial Linguistic Voices. Identity Choices and Representations. Berlin: De Gruyter Mouton, 2011. p. 99-117.

FIRMINO, G. A Situação do Português no Contexto Multilingue de Moçambique.

(Manuscrito). Universidade de São Paulo: FFLCH, 2010. 
FIRMinO, G. A "Questão Linguística” na África Pós-Colonial: O caso do Português e das Línguas Autóctones em Moçambique. Maputo: Promédia, 2002.

GONÇALVES, P. A génese do Português de Moçambique. Lisboa: INCM, 2010.

GUISSEMO, M. Manufacturing Multilingualisms of Marginality in Mozambique. Exploring the Orders of Visibility of Local African Languages. 2018. (Doctoral Dissertation). Stockholm: Stockholm University, 2018.

HAUPT, A. Citizenship without representation? Blackface, misogyny and parody. COMMUNICATIO, [s.l.], v. 39, n.4, p. 466-482, 2013.

HEINE, B. Vertical and horizontal Communication in Africa. Africa Spectrum, [s.l.],v. 12, n.3, p. 231-238, 1977.

HELLER, M. Paths to Post-Nationalism. A Critical Ethnography of Language and Identity. Oxford: Oxford University Press, 2011.

INSTITUTO NACIONAL DE ESTATÍSTICA (INE). IV Recenseamento Geral da População e Habitação 2017. Resultados Definitivos Moçambique. Maputo: INE, 2019.

IRVINE, J. When Talk Isn't Cheap: Language and Political Economy. American Ethnologist, [s.l.], n. 16, p. 248-267, 1989.

JORNAL NOTÍCIAS, Edição n. 30.961, Quinta-feira, 16 abril. 2020.

KAMWANGAMALU, N. Language ideologies and practices in Africa. Journal of Sociolinguistics, [s.l.], [s.n.], p. 1-12, 2019.

KERFOOT, C.; HYLTENSTAM, K. Introduction: Entanglement and Orders of Visibility. In: KERFOOT, C.; HYLTENSTAM, K. (ed.). Entangled Discourses: South-North Orders of Visibility. New York: Routledge, 2017. p. 1-13.

LANDRY, R.; BOURHIS, R. Linguistic Landscape and Ethnolinguistic Vitality: An Empirical Study. Journal of Language and Social Psychology, [s.1.], v. 16, n.1, p. 23-49, 1997.

LOPES, A. The Battle of the Languages: Perspectives on Applied Linguistics in Mozambique. Maputo: Imprensa Universitária, 2004.

MADUMUlLA, J.; BERTONCINI, E.; BLOMMAERT, J. Politics, Ideology and Poetic Form: The Literary Debate in Tanzania. In: BLOMMAERT, J. (ed.). Language Ideological Debates. Berlin: Mouton de Gruyter, 1999. p. 307-341.

MAKONI, S.; MEINHOF, U. Introducing Applied Linguistics in Africa. In: MAKONI, S.; MEINHOF, U (ed.). Africa and Applied Linguistics. Amsterdam: John Benjamins Publishing Company, 2003. p. 1-12.

PENNYCOOK, A.; MITCHELL, T. Hip Hop as Dusty Foot Philosophy: Engaging Locality. In: SAMY ALIM, H.; IBRAHIM, A.; PENNYCOOK, A. (ed.). Global Linguistic Flows. Hip Hop Cultures, Youth Identities, and the Politics of Language. London: Routledge, 2009. p. 25-42.

REITE, T. From racial to linguistic social divisions: Coloniality in contemporary Maputo. Journal of Sociolinguistics, [s.l.], n. 00(1), p. 1-19, 2021.

REITE, T.; OLOKO, F.; GUISSEMO, M. Fluid Multilingual Practices amongst Youth in Camaroon and Mozambique. In: SWARTZ, S.; COOPER, A.; BATAN, C.; CAUSA, L. (ed.). The Handbook of Global South Youth Studies. Oxford: Oxford University Press, 2020. p. 357-369. 
ROSÁRIO, L. A Língua Portuguesa como Factor de Desenvolvimento Nacional e Afirmação Internacional - Que Desafios? In: GONÇALVES, P.; CHIMBUTANE, F. (org.). Multilinguismo e Multiculturalismo em Moçambique: em Direcção a uma Coerência entre Discurso e Prática. Maputo: Alcance Editores, 2015. p. 23-34.

RUIZ, R. Language Planning Considerations in Indigenous Communities. The Bilingual Research Journal, [s.l.], v. 19, n. 1, p. 71-81, 1995.

STROUD, C. Bilingualism: Colonialism and Postcolonialism. In: HELLER, M. (ed.). Bilingualism: A Social Approach. London: Palgrave Macmillan, 2007. p. 25-49.

STROUD, C. Flaming Bourdieu Socioculturally: Alternative Forms of Linguistic Legitimacy in Postcolonial Mozambique. Multilingua, [s.1.], v. 21, p. 247-273, 2002.

STROUD, C. African mother-tongue programmes and the politics of language: Linguistic Citizenship versus Linguistic Human Rights. Journal of Multilingual and Multicultural Development, [s.1.], v. 22, n. 4, p. 339-355, 2001.

STROUD, C. Portuguese as Ideology and politics in Mozambique: Semiotic (Re)constructions of a Postcolony. In: BLOMMAERT, J. (ed.). Language Ideological Debates. Berlin: Mouton de Gruyter, 1999. p. 343-380.

STROUD, C.; GUISSEMO, M. Linguistic Messianism: Multilingualism in Mozambique. In: EBONGUE, A.; HURST, E. (ed.). Sociolinguistics in African Contexts, Multilingual Education 20. Gewerbestrasse 11: Springer international Publishing, 2017. p. $35-$ 51.

STROUD, C.; GUISSEMO, M. Linguistic Messianism. Multilingual Margins, [s.l.], v. 2, n.2, p. 7-21, 2015.

WOOLARD, K. Is the Past a Foreign Country? Time, Language Origins, and the Nation in Early Modern Spain. Journal of Linguistic Anthropology, [s.l.], v. 14, n.1, p. 57-80, 2004.

\section{(ㄷ) (1) $\circledast$}

Recebido em 05/05/2021. Aceito em 27/11/2021. 